\title{
From Hongkew Recreation Ground to Bird's Nest: the Past, Present and Future of Large Sports Venues in China
}

\author{
Lu Zhouxiang, \\ National University of Ireland, Maynooth \\ Email: zhouxiang.lu@nuim.ie
}

The rapid development of western sports in China in the early $20^{\text {th }}$ century gave rise to modern sports venues and facilities. During the past one hundred years, an increasing number of large sports complexes were built around the country to facilitate the development of sport and serve the mission of modernisation. This article examines the origins and development of large sports venues in China in the context of history, politics and society. State-funded sports facilities laid the foundation for the development of sport in China. However, due to the high operating cost and the lack of commercialised sporting events, many sports venues suffered severe financial losses. On one hand, it was believed by the academia and the general public that the government should change its 'elite sport first' strategy and avoid the oversupply of large sports venues. On the other hand, we should bear in mind that large sports fixtures are important to the welfare of the society. Their social, cultural and economic values should not be measured by a model that is based solely on cost and profit. Considering China's booming consumer market and the further development of sport industry, it is evident that a strong spectator sports market will take shape and the long-term future of China's large sports venues is likely to be bright.

Keywords: large sports venue; spectator sports; history; China 
Western physical culture and competitive sports were brought to China in the late 19th century. Christianity was a main moral and intellectual force behind the spread of modern sport in China. ${ }^{1}$ Together with the government's effort to promote Western military gymnastics and physical exercises, Western missionaries made a great contribution to the development of the Anglo-American model of competitive sport. ${ }^{2}$

After defeat by the Western imperialist powers, the Treaty of Whampoa (1844) and the Treaty of Tianjin (1858) forced the Qing government to agree the free propagation of Christianity and the freedom of movement for all missionaries. Thus the second half of the 19th century saw the expansion of missionary works in the form of missionary societies and organisations. Thousands of churches were built in China. The Young Men's Christian Association (YMCA) and The Young Women's Christian Association (YWCA) made their presence in major city such as Tianjin, Beijing, Shanghai and Fuzhou. Schools were set up by missionaries to aid the propagation of Christianity. ${ }^{3}$ The YMCA and the YWCA played a leading role in organising and facilitating sport and physical education programmes. They carried out physicalculture programmes in urban China, and these were also available to rural areas indirectly. Organised-sport development came into being. Modern competitive sports such as track and field, tennis, basketball and soccer were practised in most of the church-affiliated schools. ${ }^{4}$ With the effort of these Christian organizations, Western competitive athletics flourished in many cities. Simultaneously, modern sports facilities, including baseball fields, tennis courts, football pitches and running tracks and playgrounds were built by Christian schools and YMCA clubhouses to facilitate the development of sport and physical education. ${ }^{5}$ 


\section{The Rise of Large Sports Venues in the First Half of the 20th Century}

By the 1910s, modern sports had taken its root in major cities in China. The YMCA, YWCA and other Christian organisations began to organise athletic competitions that included representatives from non-Christian institutions. ${ }^{6}$ However, no proper sports stadia/arenas were built to serve this purpose. Regional and national athletic meetings were held on temporary mud athletic tracks or lawns. For example, China's First National Games, which took place in Nanjing in October 1910, was held on a temporary athletic track on the national Nanyang Commodity Exposition site. The first Northern China Athletic Meeting (NCAM) was held on the lawn of Beijing's Tiantan Park in 1913. ${ }^{7}$

Shanghai Hongkew Recreation Ground was probably the earliest and best large sports complex in China in the 1910s. It was designed by British architect W. Lnnes Stuckey and was built by the Bureau of Construction of Shanghai International Settlement on the site of the Municipal Rifle Range, which was mostly used by the Shanghai Volunteer Corps. Modelled on a park in Glasgow, the theme of the Park was sport, leisure and entertainment. It has several football pitches and tennis courts, a swimming pool and a golf course. Construction on the facility started in 1905. It was opened to Western people in $1909 .{ }^{8}$ Chinese people, except Westerner's servants, were not allowed to enter the Ground until $1911 .{ }^{9}$ In order to host the $2^{\text {nd }}$ Far Eastern Championship Games (FECG) organised by the YMCA, an athletic track and a stadium were added to the Park in $1915 .{ }^{10}$ As the best sports complex in China, Hongkew Recreation Ground (renamed as Hongkew Park in 1921) had again became the venue of the Fifth Far Eastern Championship Games in 1921. 